\title{
Nitrogen Doped Superactivated Carbons Prepared at Mild Conditions as Electrodes for Supercapacitors in Organic Electrolyte
}

\author{
María José Mostazo-López ${ }^{1}{ }^{\circledR}$, Ramiro Ruiz-Rosas ${ }^{1}{ }^{[}$, Tomomi Tagaya ${ }^{2}$, \\ Yoshikiyo Hatakeyama ${ }^{2}$, Soshi Shiraishi ${ }^{2}$, Emilia Morallón ${ }^{3}$ (D) and \\ Diego Cazorla-Amorós ${ }^{1, * \mathbb{D}}$ \\ 1 Departamento de Química Inorgánica and Instituto Universitario de Materiales, Universidad de Alicante, \\ Apartado 99, 03080-Alicante, Spain; mj.mostazo@ua.es (M.J.M.-L.); ramiro@ua.es (R.R.-R.) \\ 2 Division of Molecular Science, Graduate School of Science and Technology, Gunma University, \\ Gunma 376-8515, Japan; t181a059@gunma-u.ac.jp (T.T.); y-htkym@gunma-u.ac.jp (Y.H.); \\ soshishiraishi3@gunma-u.ac.jp (S.S.) \\ 3 Departamento de Química Física and Instituto Universitario de Materiales, Universidad de Alicante, \\ Apartado 99, 03080-Alicante, Spain; morallon@ua.es \\ * Correspondence: cazorla@ua.es
}

Received: 10 August 2020; Accepted: 17 September 2020; Published: 20 September 2020

\begin{abstract}
Nitrogen functionalization of a highly microporous activated carbon $\left(\mathrm{S}_{\mathrm{BET}}>3000 \mathrm{~m}^{2} / \mathrm{g}\right)$, to be used as electrode of electric double layer capacitor (EDLC), was carried out by different methods based on organic chemistry protocols at low temperature and selective thermal post-treatments under inert atmosphere. The combination of both methods allowed the production of carbon materials with very similar surface area $\left(2400-3000 \mathrm{~m}^{2} / \mathrm{g}\right)$ and different surface chemistry. The nitrogen functionalization by chemical methods produce the attachment of 4 at. \% N (XPS) by consumption of oxygen functional groups. The thermal treatments rearrange the surface chemistry by decreasing and converting both nitrogen and oxygen moieties. The effect of surface chemistry on the performance of these materials as electrodes for symmetric supercapacitors was analyzed in organic electrolyte ( $1 \mathrm{M} \mathrm{TEMABF} /$ propylene carbonate). The devices showed high gravimetric capacitance (37-40 F/g) and gravimetric energy density (31-37 Wh/kg). The electrochemical stability of the EDLC was evaluated by a floating test under severe conditions of voltage and temperature. The results evidence an improvement of the durability of nitrogen-doped activated carbons modified by chemical treatments due to the decrease of detrimental oxygen functionalities and the generation of nitrogen groups with higher electrochemical stability.
\end{abstract}

Keywords: electric double layer capacitor; porous carbon; nitrogen doping; surface chemistry

\section{Introduction}

Electrochemical capacitors (supercapacitors) are energy storage devices of great interest mainly due to their high power density, durability and broad operation temperature range [1,2]. However, it is necessary to increase their energy density for enabling their use in a wider range of applications. This requires the use of electrode materials and electrolytes able to increase both the capacitance and the operation voltage of electrochemical capacitors. Regarding the electrode materials, carbon materials are the most commonly used for the electric double layer capacitor (EDLC) as a carbon-based symmetric electrochemical capacitor since they have a well-developed porosity, electrochemical stability, and tunable surface chemistry [3,4]. In case of the electrolyte, the use of non-aqueous electrolytes (organic electrolytes and ionic liquids) has attracted great interest as consequence of their possible use at 
high operation voltage [5,6]. The higher voltage charge realizes the higher energy density. Nonetheless, the use of excessively high operation voltage dramatically affects the performance of the electrodes, since carbon materials undergo reactions with the electrolyte that decrease their electrochemical stability, and consequently, diminish the cycle life of the device [7-9]. Hence, the development of carbon materials with improved electrochemical stability and durability is highly needed for their use in electrochemical capacitors.

The performance of carbon materials can be enhanced by different strategies [10]. One of the main approaches consists in synthesizing materials doped with different heteroatoms [11,12], such as sulfur, phosphorus or nitrogen, since they modify the electrochemical behavior of the material [7,13-16]. More specifically, nitrogen doping can increase the wettability, conductivity, and electrochemical stability [7,8,17-20]. However, the role of the different nitrogen groups is not still well understood. The isolation of selective functional groups on the surface of carbon materials is still a challenge since the formation of different functionalities depends on the temperature treatment and coexist with other surface groups. Moreover, the most common methods for producing nitrogen-doped carbon materials usually affect other key parameters on the performance of carbon electrodes: the porous structure and the oxygen functional groups [21,22]. Thus, understanding of the effect of nitrogen groups requires an ideal preservation of both oxygen functional groups and porous texture.

Nitrogen doped carbon materials can be prepared by several methods [23-27] that can be classified as follows: (i) by using a nitrogen-containing compound as additive or even as carbon source in different synthesis methods, such as carbonization (followed by activation) or templating methods; (ii) through post-treatments of a material previously synthesized with a nitrogen-containing reactant in gas or liquid phase. The latter methods usually involve the use of high temperatures to favor the incorporation of nitrogen, whether in gas or liquid phase. Moreover, the temperature treatment strongly affects the porosity of carbon material and produces other changes on the surface chemistry, such as the modification (via removal, attachment, or transformation) of oxygen functional groups. Thus, the attachment of nitrogen moieties while preserving other properties requires the use of less common methodologies. In this sense, the post-modification of the surface chemistry of carbon materials using strategies based on organic chemistry protocols is especially interesting, mainly because the incorporation of nitrogen is produced via consumption of oxygen groups and consequently the porous texture remains invariable. The modification of porosity is only a consequence of the amount and size of the nitrogen groups that have been incorporated. In this sense, we have developed nitrogen functionalization methods at mild conditions that allow the incorporation of a wide range of nitrogen functionalities while preserving the structure of the pristine carbon material, even when using carbon materials with extraordinary microporosity $[9,28]$. Moreover, the method also modifies porous carbon monolith, of which the interior is not easy to react with chemicals, such as seamless activated carbon electrodes [29]. These nitrogen-doped carbon materials can be used as a platform for producing selective nitrogen functional groups by heat treatments at selective temperatures under conditions that only the desorption of surface groups is produced, and consequently, the porosity remains invariable. Thus, an accurate selection of surface chemistry modification methods can be considered as an adequate strategy to produce highly microporous carbon materials with very similar porous texture and specific functional groups.

The aim of this work is to elucidate the role of different nitrogen functionalities on the performance of activated carbons as electrodes for the EDLC using organic electrolyte, mainly focusing on their effect on the electrochemical stability and durability of the device. We propose the synthesis of nitrogen-doped activated carbons with high apparent surface area by combining functionalization methods based on wet methods at low temperatures and post-thermal treatments at different temperatures, whose combination allows a selective modification of the surface chemistry. The effect of different nitrogen functionalities and doping methods on the performance of these materials as electrodes for the EDLC is tested in typical organic electrolyte and severe conditions of temperature and operation voltage. 


\section{Materials and Methods}

\subsection{Synthesis of Carbon Materials}

\subsubsection{Pristine Carbon Material}

An activated carbon with high microporosity prepared in our laboratory has been used as the starting material for nitrogen incorporation via post-modification treatments. The pristine material (named as KUA) has been synthesized by chemical activation of a Spanish anthracite with $\mathrm{KOH}$ (CAS number: 1310-58-3, 85\%, AnalaR Normapur, VWR Chemicals, USA) using an impregnation ratio of activating agent to raw material of $4: 1$ and an activation temperature of $750{ }^{\circ} \mathrm{C}$ under inert atmosphere, which was held for $1 \mathrm{~h}$. More details about the preparation process are available elsewhere [30].

\subsubsection{N-Functionalization of Carbon Materials at Mild Conditions}

KUA was further functionalized with nitrogen functional groups by two different approaches based on the organic chemistry reactions described in refs. $[9,28]$. The first approach consisted in a three-step protocol combining oxidation and amidation reactions, that is described as follows:

(i) Oxidation treatment. $1 \mathrm{~g}$ of activated carbon (KUA) was mixed with $40 \mathrm{~mL}$ of $\mathrm{HNO}_{3} 65 \mathrm{wt} \%$ under stirring during $3 \mathrm{~h}$ at room temperature. After that, the activated carbon was filtrated and washed with Milli-Q water until the $\mathrm{pH}$ of elution was neutral. Finally, the sample (named KUA-COOH) was dried at $100{ }^{\circ} \mathrm{C}$.

(ii) Treatment with $\mathrm{SOCl}_{2} .1 \mathrm{~g}$ of $\mathrm{KUA}-\mathrm{COOH}$ was introduced in a round bottom flask with $50 \mathrm{~mL}$ of toluene and $5 \mathrm{~mL}$ of $\mathrm{SOCl}_{2}$ (CAS number: 7719-09-7, 97\%, Sigma-Aldrich, Saint Louis, MO, USA) was added to the flask. The mixture was refluxed at $120^{\circ} \mathrm{C}$ for $5 \mathrm{~h}$ and finally washed with toluene and dried for $14 \mathrm{~h}$.

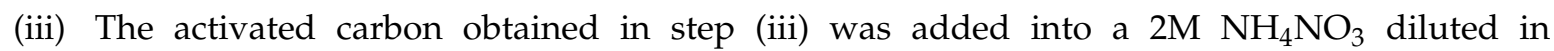
N,N-dymethilformamide (CAS number: 68-12-2, Sigma-Aldrich, EEUU) in a round bottom flask, using an activated carbon to solution ratio of $1 \mathrm{~g} / 150 \mathrm{~mL}$. Then, $150 \mathrm{~mL}$ of pyridine (CAS number: 110-86-1, 99\%, Acros Organics, Fisher Scientific, Waltham, MA, USA) were added slowly to the round bottom flask under continuous stirring at room temperature. The mixture was stirred at $70{ }^{\circ} \mathrm{C}$ for $65 \mathrm{~h}$. The obtained amidated sample $\left(\mathrm{KUA}-\mathrm{CONH}_{2}\right)$ was washed with abundant water and ethanol, filtered, and dried at $100{ }^{\circ} \mathrm{C}$ overnight.

In the second approach, the amidation reaction (third step of the first method) is directly applied over pristine sample (KUA). This sample was named as KUA-N. More details about the preparation methods are found elsewhere $[9,28]$.

\subsubsection{Heat Treatments}

The carbon materials (KUA, $\mathrm{KUA}-\mathrm{CONH}_{2}$ and $\mathrm{KUA}-\mathrm{N}$ samples) were heat treated at two different temperatures for $1 \mathrm{~h}$ under $\mathrm{N}_{2}$ atmosphere using a flow of $200 \mathrm{~mL} / \mathrm{min}$ and a heating rate of $5{ }^{\circ} \mathrm{C} / \mathrm{min}$. The obtained samples were labelled as KUA_n, KUA-CONH $2 \_n$ and KUA-N_n, where $\mathrm{n}$ is the final heating temperature $\left(500\right.$ and $\left.800{ }^{\circ} \mathrm{C}\right)$.

\subsection{Physicochemical Characterization}

The surface chemistry of the samples was analyzed by X-ray photoelectron spectroscopy (XPS) and temperature programmed desorption (TPD). XPS analyses were performed using a VG-Microtech Multilab 3000 spectrometer with an Al anode. N1s spectra were deconvoluted using Gaussian functions with $20 \%$ of Lorentzian component. A Shirley line was used as background and the FWHM of the peaks was kept between 1.4 and $1.7 \mathrm{eV}$. The experimental error is $\pm 0.2 \mathrm{eV}$. TPD experiments were carried out using a TGA-DSC instrument (TA Instruments, SDT Q600 Simultaneous) coupled to a mass spectrometer (Thermostar, Balzers, BSC 200, Asslar, Germany), by heating the samples up to $950^{\circ} \mathrm{C}$ 
(heating rate: $20^{\circ} \mathrm{C} / \mathrm{min}$ ) under helium atmosphere (flow rate: $100 \mathrm{~mL} / \mathrm{min}$ ). The experimental error in this technique is $\pm 10 \mu \mathrm{mol} / \mathrm{g}$.

The porous texture characterization was carried out by $\mathrm{N}_{2}$ adsorption-desorption isotherms at $-196{ }^{\circ} \mathrm{C}$ and by $\mathrm{CO}_{2}$ adsorption at $0{ }^{\circ} \mathrm{C}$ using an Autosorb-6-Quantachrome apparatus. The samples were outgassed at $200{ }^{\circ} \mathrm{C}$ for $4 \mathrm{~h}$ before the experiments. The apparent surface area was obtained from $\mathrm{N}_{2}$ adsorption isotherms by using the BET equation in the $0.05-0.20$ range of relative pressures. The total micropore volume was determined by Dubinin-Radushkevich (DR) method applied to $\mathrm{N}_{2}$ (relative pressures from 0.01 to 0.05 ) adsorption isotherms. The volume of the narrow microporosity (i.e., pore sizes below $0.7 \mathrm{~nm}$ ) was calculated from the DR method applied to the $\mathrm{CO}_{2}$ adsorption isotherms (relative pressures from 0.0001 to 0.20 ) [31]. The experimental errors are $\pm 0.01 \mathrm{~cm}^{3} / \mathrm{g}$ for micropore volume $\left(\mathrm{V}_{\mathrm{DR}}\right)$ and $\pm 10 \mathrm{~m}^{2} / \mathrm{g}$ for apparent surface area $\left(\mathrm{S}_{\mathrm{BET}}\right)$, also taking into account the reproducibility of the measurement.

\subsection{Electrochemical Characterization}

The carbon materials were used for the preparation of the electrodes for two-electrode sealed cells (Al/Mg-body flat cell, Hohsen Corporation, Osaka, Japan). The electrodes were prepared by mixing the carbon material with acetylene black and polytetrafluoroethylene (PTFE) in a ratio of 85:10:5 wt \%. The electrodes were pressed to shape disks with a diameter of $13 \mathrm{~mm}$ and a thickness of $\sim 0.5 \mathrm{~mm}$ (net weight: $35 \mathrm{mg}$ ). Etched aluminium foil (20C054, Japan Capacitor Industrial Co., Ltd., Tokyo, Japan) as current collector was attached to the electrode by using conductive carbon paste (GA-715, Hitachi Chemical Co., Ltd., Tokyo, Japan). Cellulose fiber paper was used as separator and $1 \mathrm{M}$ triethylmethylamonium tetrafluoroborate diluted in propylene carbonate (TEMA-BF $4 / \mathrm{PC}_{\text {, }}$ Toyo Gosei Co., Ltd., Tokyo, Japan) as electrolyte. The cells were assembled with the two identical electrodes as positive and negative electrode, the separator, and the electrolyte inside an Argon glovebox.

All electrochemical characterization was conducted using charge-discharge system (HJ-1001SM8, Hokuto Denko Co., Tokyo, Japan). The cells were tested by galvanostatic charge-discharge (GCD) cycles between $0-2.5 \mathrm{~V}$ with different current densities $(40,100,200,400,600,1000 \mathrm{~mA} / \mathrm{g})$ at $40{ }^{\circ} \mathrm{C}$. These current densities were determined by normalizing the actual current value with the total active mass of the carbon in both of the positive and negative electrodes in the full cell. The capacitance was calculated from the discharge curve of the GCD cycles as reported previously in the literature [32]. The capacitance values are given with an experimental error of $\pm 1 \mathrm{~F} / \mathrm{g}$. The gravimetric capacitance is referred to the total active mass of the carbon in the cell in the same manner as the current density. Afterwards, a durability test (based on GCD cycles and floating test) was performed by applying the following procedure: (i) $5 \mathrm{GCD}$ cycles at $2.5 \mathrm{~V}$ and $40^{\circ} \mathrm{C}$; (ii) $5 \mathrm{GCD}$ cycles at $2.5 \mathrm{~V}$ and $70^{\circ} \mathrm{C}$; (iii) $5 \mathrm{GCD}$ cycles at $3.2 \mathrm{~V}$ and $70^{\circ} \mathrm{C}$; (iv) voltage is kept at $3.2 \mathrm{~V}$ for $100 \mathrm{~h}$ (floating test). After finishing the floating test (iv), steps (iii), (ii) and (i) were subsequently repeated. The capacitance, internal resistance and integrated leakage current were calculated. The retention of capacitance is given at $2.5 \mathrm{~V}$ and $40^{\circ} \mathrm{C}$. The current density was kept as $40 \mathrm{~mA} / \mathrm{g}$ during the experiment.

\section{Results and Discussion}

\subsection{Physicochemical Characterization of Carbon Materials}

\subsubsection{Porous Texture}

Figure 1 illustrates the $\mathrm{N}_{2}$ adsorption-desorption isotherms obtained for all activated carbons. The profiles evidence that all carbon materials show an adsorption-desorption curve characteristic of microporous materials. Table 1 summarizes the porous texture parameters obtained from $\mathrm{N}_{2}$ and $\mathrm{CO}_{2}$ isotherms for all the activated carbons; the pristine sample $\mathrm{KUA}$, the treated at $800{ }^{\circ} \mathrm{C}$ (KUA_800) and the oxidized in nitric acid (KUA_COOH) have been included for comparison purposes. The changes in the porous texture of the samples obtained by oxidation (KUA-COOH) and chemical 
functionalization (KUA-CONH 2 and $\mathrm{KUA}-\mathrm{N}$ ) were previously discussed $[9,28]$. The most significant change is observed for $\mathrm{KUA}-\mathrm{COOH}$ and $\mathrm{KUA}-\mathrm{CONH}_{2}$ samples, as consequence of the generation of oxygen functionalities in $\mathrm{KUA}-\mathrm{COOH}$ and their conversion into nitrogen functional groups that occupy or block part of the microporosity [28] (Table 1, Figure 2b,c). However, when the chemical method is directly applied over the pristine sample (sample KUA-N), the microporosity of the material is fully preserved (as demonstrated in Figure 1a, Table 1).
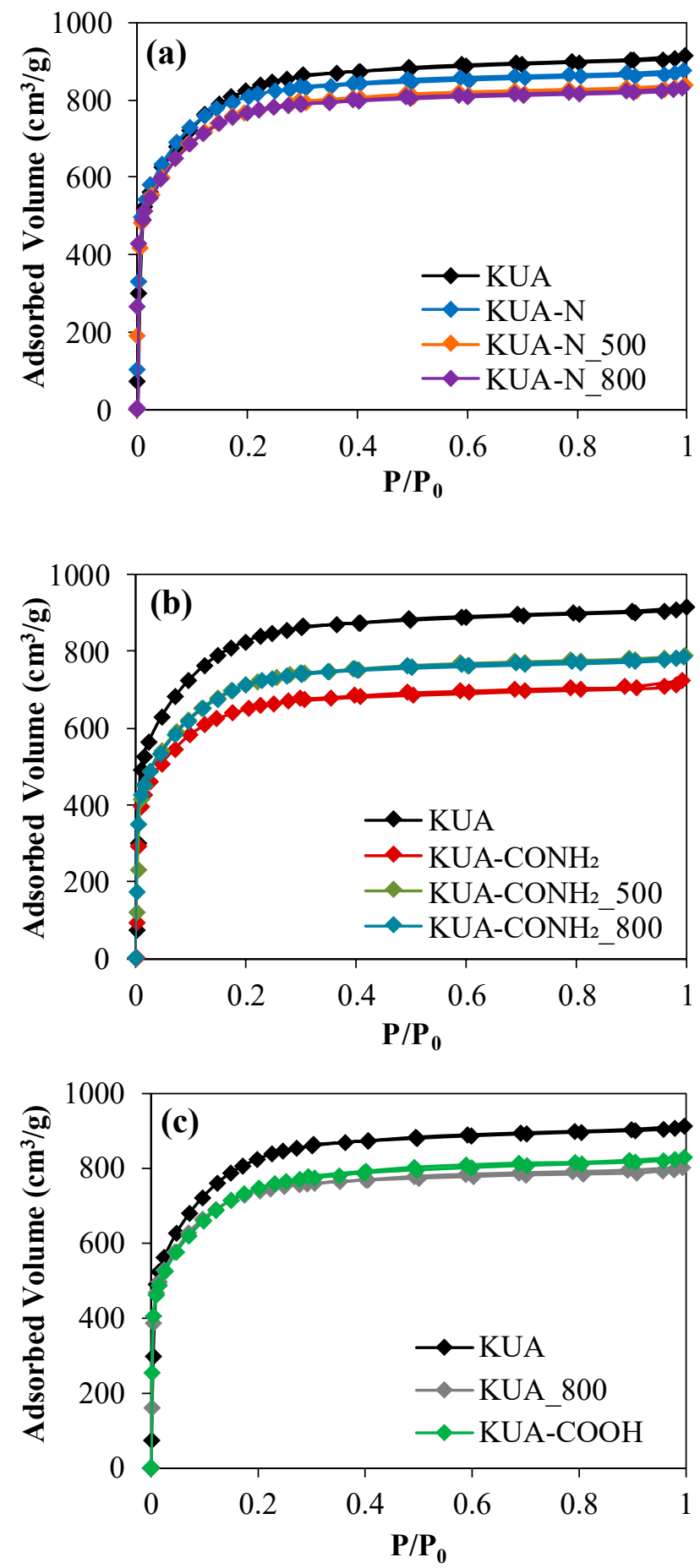

Figure 1. $\mathrm{N}_{2}$ adsorption-desorption isotherms obtained for all activated carbons: (a) KUA, KUA-N and related heat-treated samples, (b) KUA, $\mathrm{KUA}-\mathrm{CONH}_{2}$ and related heat-treated samples, (c) KUA and related heat-treated sample. 
Table 1. Porous texture of the activated carbons.

\begin{tabular}{cccc}
\hline Sample & $S_{\text {BET }}\left(\mathbf{m}^{2} / \mathbf{g}\right)$ & $V_{\text {DR }}{ }^{\mathbf{N}} \mathbf{( \mathbf { c m } ^ { 3 } / \mathbf { g } )}$ & $V_{\text {DR }}{ }^{\mathbf{C O}} \mathbf{( \mathbf { c m } ^ { 3 } / \mathbf { g } )}$ \\
\hline KUA & 3080 & 1.19 & 0.57 \\
KUA_800 & 2720 & 1.05 & 0.49 \\
KUA-N & 2960 & 1.18 & 0.52 \\
KUA-N_500 & 2800 & 1.11 & 0.49 \\
KUA-N_800 & 2770 & 1.09 & 0.48 \\
KUA-COOH & 2770 & 1.06 & 0.49 \\
KUA-CONH & 2390 & 0.97 & 0.45 \\
KUA-CONH 2 500 & 2630 & 1.02 & 0.41 \\
KUA-CONH2_800 & 2630 & 1.0 & 0.43 \\
\hline
\end{tabular}
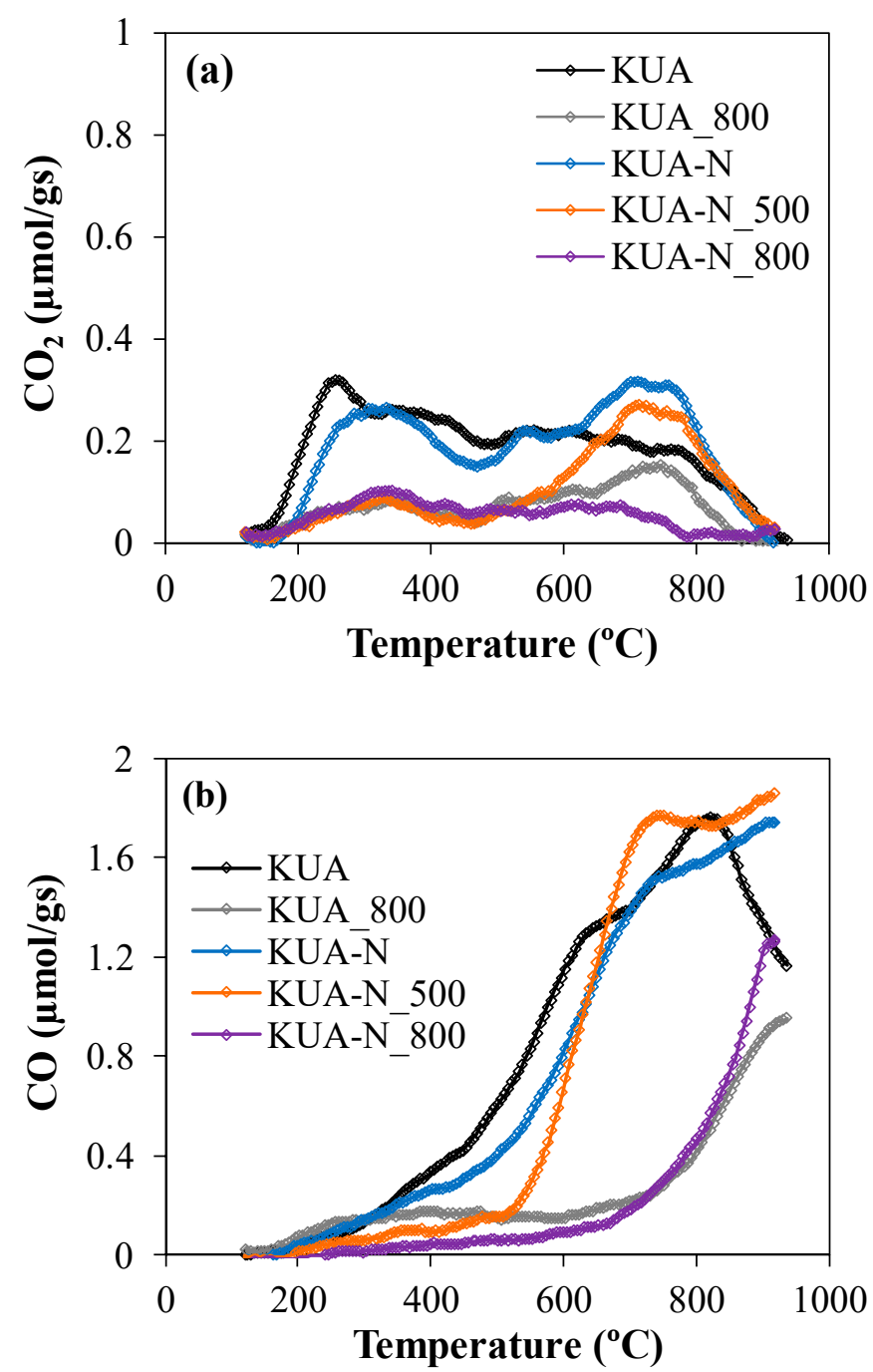

Figure 2. Comparison between (a) $\mathrm{CO}_{2}$ and (b) $\mathrm{CO}$ TPD profiles of KUA, KUA_800, KUA-N, KUA-N_500 and KUA-N_800.

Regarding the heat-treated samples, some loss of the microporosity is detected when the heat treatment is carried out over KUA and KUA-N samples (Figure 1a,c, Table 1). This change could be produced by some structural rearrangement in the materials [33]. However, the heat treatments over $\mathrm{KUA}-\mathrm{CONH}_{2}$ produce an increase of the micropore volume (see samples $\mathrm{KUA}-\mathrm{CONH}_{2} \_500$ and $\mathrm{KUA}-\mathrm{CONH}_{2}$ 800). This increase of microporosity is related to the removal of functional groups that occupy or block part of the microporosity in the pristine sample. Interestingly, the thermal treatments at different temperatures $\left(500{ }^{\circ} \mathrm{C}\right.$ and $\left.800{ }^{\circ} \mathrm{C}\right)$ produce identical modifications on the 
porous texture of the pristine sample (KUA-N and $\mathrm{KUA}-\mathrm{CONH} \mathrm{KN}_{2}$ ). As consequence, the $\mathrm{N}_{2}$ adsorption isotherms obtained for samples KUA-N_500 and KUA-N_800 overlaps (Figure 1a). The same effect is observed for KUA-CONH${ }_{2} \_500$ and $\mathrm{KUA}_{-} \mathrm{CONH}_{2} \_800$ samples (Figure 1b). The identical textural properties produced by the heat treatments at different temperatures indicate that the main textural rearrangements are produced at temperatures below $500{ }^{\circ} \mathrm{C}$ at the range of temperatures used.

The $\mathrm{CO}_{2}$ micropore volumes (collected in Table 1) provide information about the narrow microporosity of the samples $(<0.7 \mathrm{~nm})$ [31]. It is observed that the chemical functionalization and the heat treatments produce a small decrease of the narrow microporosity. The largest micropore volume was found for the pristine sample KUA, followed by the KUA-N activated carbon and its related heat-treated samples (KUA-N_500 and KUA-N_800).

The pore size distribution was analyzed and is shown in the Supplementary Data (Figure S1). The pristine carbon material displays a wide pore size distribution and an average pore size of $1.4 \mathrm{~nm}$. The surface modification methods do not produce significant changes in the pore size distribution of the functionalized carbons. The profiles show that the modification treatments mainly affect the largest micropores $(>1 \mathrm{~nm})$, while the narrowest micropores remain almost invariable. However, KUA-N activated carbon (and its related heat treated samples) experience an increase of the amount of micropores below $1 \mathrm{~nm}$, indicating that the functionalization method produces the occupation of the largest micropores and, in consequence, decreases their size.

\subsubsection{Surface Chemistry Characterization}

The surface chemistry of the activated carbons was characterized by XPS and TPD. Table 2 collects the data related to the chemical composition of the samples. Figures 2 and 3 collect the TPD profiles obtained for all activated carbons. The pristine carbon material KUA possesses a large amount of oxygen functionalities that decompose mainly as $\mathrm{CO}$ and in lower extent as $\mathrm{CO}_{2}$ (Figure 2). The chemical modification methods produce the attachment of nitrogen to the surface of the pristine activated carbon by consumption of oxygen functional groups, as confirmed by XPS (Table 2). Figure 4 shows the deconvoluted N1s spectra obtained for all N-doped activated carbons and Table 3 summarizes the relative amount of the detected $\mathrm{N}$ functional groups. In case of KUA-N sample, the attachment of nitrogen occurs directly over the pristine carbon material via reaction mainly with $\mathrm{CO}-e v o l v i n g$ groups. Thus, this treatment produces nitrogen groups derived from these oxygen functionalities, such as imines, amines and $\mathrm{N}$ heterocycles (pyrroles, pyridones, and pyridines) [25,34-36] (Figure 2a). In the case of the $\mathrm{KUA}^{-C O N H} \mathrm{~N}_{2}$ sample, an oxidation treatment is carried out, previously to the incorporation of nitrogen, to increase the amount of oxygen functional groups that can react during the amidation treatment. The oxidation treatment with $\mathrm{HNO}_{3}$ produces an increase of both $\mathrm{CO}$ and $\mathrm{CO}_{2}$ evolving-groups, and consequently the nitrogen moieties produced after the nitrogen doping treatment are mainly in form of amides (and cyclic amides), pyridines, and pyrroles/pyridones [25,34-36]. Hence, both N-doped carbons obtained at mild conditions evidence the presence of different $\mathrm{N}$ functional groups, being $\mathrm{KUA}-\mathrm{CONH}_{2}$ richer in those derived from $\mathrm{CO}_{2}$-evolving groups (amides, lactams, and imides).

Table 2. Surface composition of the activated carbons obtained by XPS and TPD.

\begin{tabular}{|c|c|c|c|c|c|}
\hline Sample & $\mathrm{CO}_{2}$ TPD $(\mu \mathrm{mol} / \mathrm{g})$ & $\mathrm{CO}_{\mathrm{TPD}}(\mu \mathrm{mol} / \mathrm{g})$ & $\mathrm{O}_{\mathrm{TPD}}(\mu \mathrm{mol} / \mathrm{g})$ & $\mathrm{O}_{\text {XPS }}($ at. $\%$ ) & $\mathrm{N}_{\text {XPS }}$ (at. \%) \\
\hline KUA & 450 & 1970 & 2870 & 8.8 & 0.3 \\
\hline KUA_800 & 170 & 620 & 960 & 2.3 & \\
\hline KUA-N & 450 & 1750 & 2640 & 7.5 & 3.7 \\
\hline KUA-N_500 & 250 & 1620 & 2120 & 5.1 & 2.3 \\
\hline KUA-N_800 & 130 & 505 & 720 & 3.0 & 1.7 \\
\hline KUA-COOH & 1790 & 3770 & 7360 & 15.8 & \\
\hline $\mathrm{KUA}^{-\mathrm{CONH}_{2}}$ & 1140 & 2370 & 4650 & 10.2 & 4.2 \\
\hline KUA-CONH $2 \_500$ & 250 & 1650 & 2140 & 8.0 & 3.4 \\
\hline KUA-CONH $2 \_800$ & 140 & 570 & 830 & 4.5 & 2.1 \\
\hline
\end{tabular}


The surface chemistry of the carbon materials was subsequently modified by heat treatments under inert atmosphere to produce activated carbons with different composition while keeping unmodified the porous texture of the pristine materials. These treatments produce a decrease of oxygen and nitrogen groups (Table 2). TPD profiles allow to get information about the changes produced in the oxygen functionalities (Figures 2 and 3). When the treatment at $500{ }^{\circ} \mathrm{C}$ is carried out, some oxygen functionalities are removed from their surface; the main loss comes from $\mathrm{CO}_{2}$-evolving groups, since most part of these functionalities are not thermally stable at temperatures higher than $600{ }^{\circ} \mathrm{C}$ [37]. Thus, no significant changes are produced on KUA-N at this temperature, as a result of the small number of $\mathrm{CO}_{2}$-evolving groups in this sample. Consequently, KUA-N_500 shows a similar composition as that of KUA-N, with slightly lower oxygen content. More important differences are found for $\mathrm{KUA}-\mathrm{CONH}_{2} 500$ due to the larger amount of oxygen (specially, $\mathrm{CO}_{2}$-evolving groups) of the parent carbon (KUA-CONH${ }_{2}$ ). After the treatment, most of the $\mathrm{CO}_{2}$ groups are removed from this sample ( $80 \%$ decrease, Table 2). Moreover, an important decrease of the CO-evolving groups is also observed (30\% decrease, Table 2). Interestingly, both carbons heat-treated at $500{ }^{\circ} \mathrm{C}$ show almost identical content of oxygen groups (measured by TPD, Table 2, Figures 2 and 3). The oxygen content reported by XPS displays different values since this technique measures the atomic composition in the outer part of the carbon particles, while TPD provides the amount of $\mathrm{CO}_{2}$ and $\mathrm{CO}$ evolving groups produced by the desorption of oxygen functionalities in the inner and the outer regions of the carbon particles.
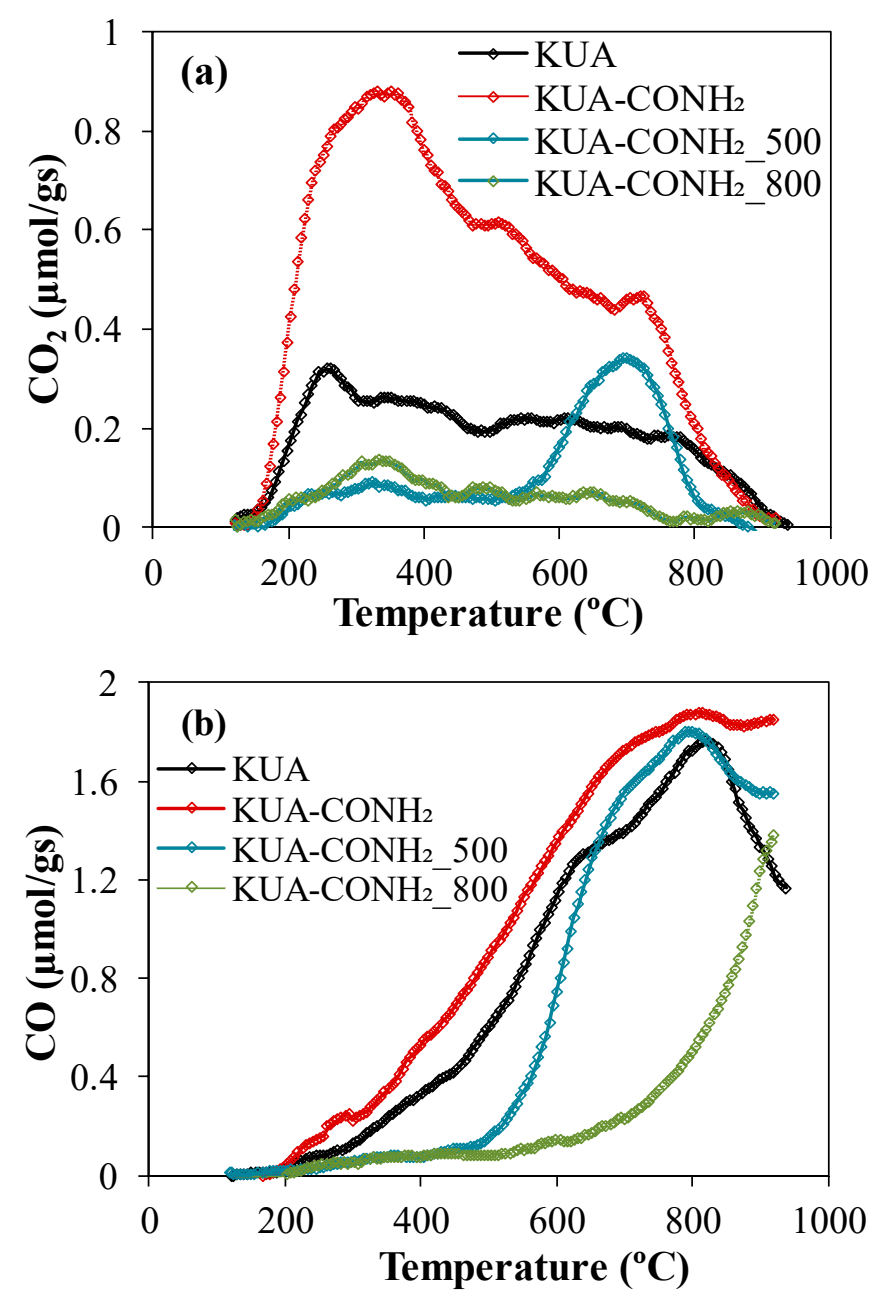

Figure 3. Comparison between (a) $\mathrm{CO}_{2}$ and (b) $\mathrm{CO}$ TPD profiles of $\mathrm{KUA}, \mathrm{KUA}-\mathrm{CONH}_{2}, \mathrm{KUA}-\mathrm{CONH}{ }_{2} \_500$ and $\mathrm{KUA}-\mathrm{CONH}_{2} 800$. 
The heat treatment at $800^{\circ} \mathrm{C}$ removes most of oxygen. Around $70-80 \%$ of oxygen functionalities are removed from KUA, KUA-N, and $\mathrm{KUA}-\mathrm{CONH}_{2}$ when they are heat treated at $800^{\circ} \mathrm{C}$. $\mathrm{N}$ functionalities also decrease upon heat treatment and around $50 \%$ of $\mathrm{N}$ remains after the treatment. Hence, the obtained samples show similar oxygen contents (mainly in form of carbonyles [37]) and an almost identical porous texture (Section 3.1.1.).
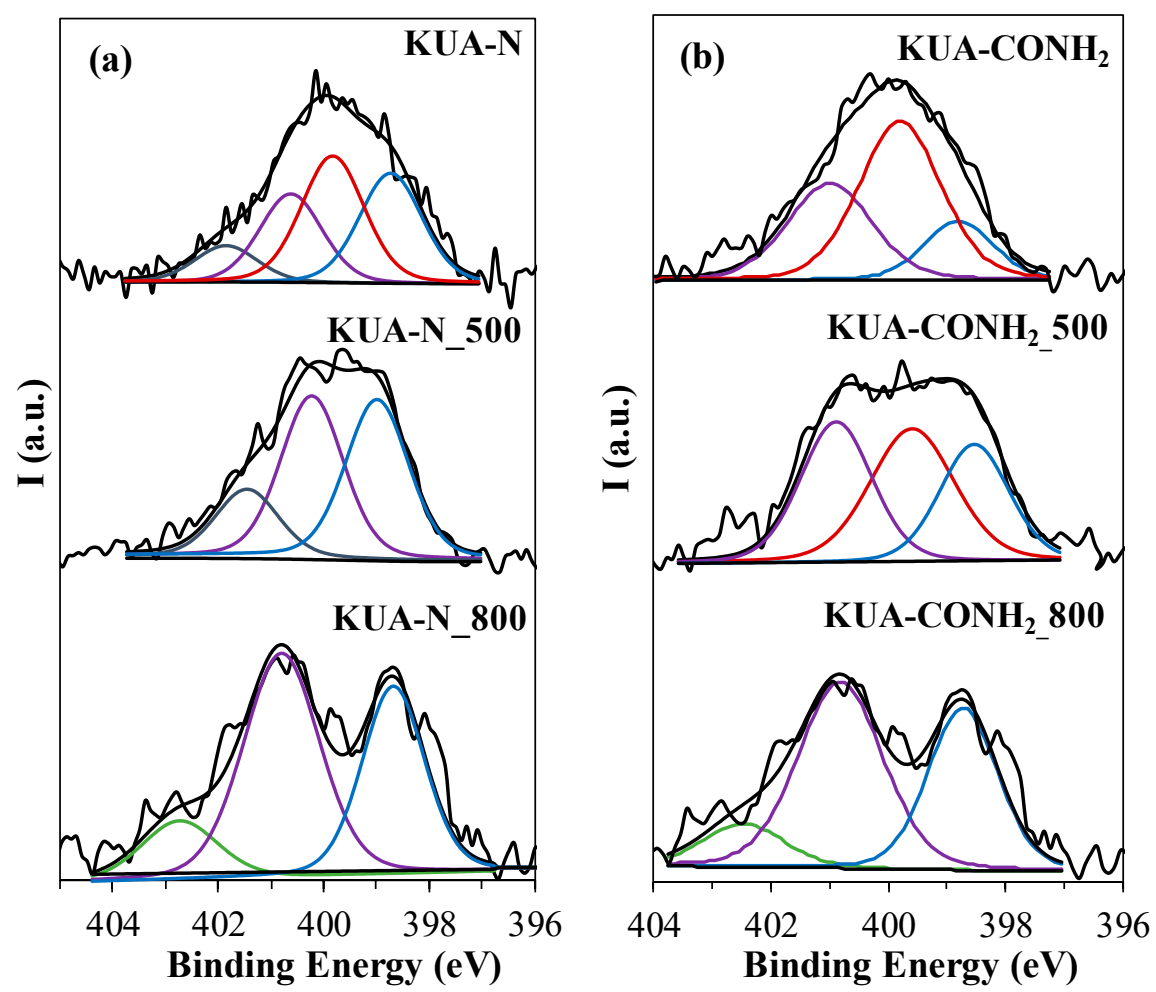

Figure 4. N1s XPS spectra deconvoluted for (a) KUA-N, KUA-N_500 and KUA-N_800 activated carbons and (b) $\mathrm{KUA}_{-} \mathrm{CONH}{ }_{2}, \mathrm{KUA}-\mathrm{CONH}_{2}$ 500 and $\mathrm{KUA}-\mathrm{CONH}{ }_{2} 800$ activated carbons.

The deconvolution of N1s XPS spectra obtained for all N-doped activated carbons allows to assess the modifications produced on the nitrogen moieties during the thermal treatments (Figure 4). Table 3 collects the ratio of each nitrogen group obtained from the N1s XPS spectra. As previously described, the N-doped carbons at mild conditions (KUA-N and $\mathrm{KUA}-\mathrm{CONH}_{2}$ ) have similar nitrogen contents but, according to the modification pathway, some of the generated groups are different. The peak at $399.8 \pm 0.2 \mathrm{eV}$ can be assigned to amides (and cyclic amides) and amines, being more likely the formation of amides in $\mathrm{KUA}-\mathrm{CONH}_{2}$ (due to the previous oxidation process) and amines in KUA-N [18].

When the samples are heat treated at $500{ }^{\circ} \mathrm{C}$, the nitrogen moieties of lower thermal stability are removed, i.e., those with a single chemical bond, such as amines and amides [38]. Indeed, the heat treatment of KUA-N produces a loss of 1.4 at. \% N (Table 2), that is in agreement with the amount of amines detected in KUA-N, and that does not appear in the spectrum of KUA-N_500 (Figure 4a), evidencing the preferential removal of this functional group during the treatment. In case of KUA-CONH 2 , a lower loss of nitrogen is detected (0.8 at. \% XPS, Table 2). Likewise, the main decrease is associated to the functional groups at $399.8 \pm 0.2 \mathrm{eV}$, i.e., amide-like functionalities (Table 3, Figure 4b), but they are still detected on $\mathrm{KUA}_{-} \mathrm{CONH}_{2} \_500$. Moreover, this sample evidences an increase of pyrrole/pyridones contribution $(400.7 \pm 0.2 \mathrm{eV})$ that can be related to the rearrangements of amides to generate pyrroles upon heating [35], explaining the higher retention of nitrogen in this sample. 
Table 3. Assignment of N1s deconvoluted curves to nitrogen functional groups.

\begin{tabular}{|c|c|c|c|c|}
\hline Sample & Binding Energy $(\mathrm{eV})$ & Functional Group & N (at. \%) & Ratio of N Species (\%) \\
\hline \multirow{4}{*}{ KUA-N } & $401.9 \pm 0.2$ & Quaternary & 0.4 & 10 \\
\hline & $400.7 \pm 0.2$ & Pyrrole, Pyridone & 0.9 & 25 \\
\hline & $399.8 \pm 0.2$ & Amide, Lactam, Amine, Imide & 1.3 & 35 \\
\hline & $398.7 \pm 0.2$ & Pyridine, Imine & 1.1 & 30 \\
\hline \multirow{4}{*}{ KUA-N_500 } & $401.5 \pm 0.2$ & Quaternary & 0.4 & 17 \\
\hline & $400.2 \pm 0.2$ & Pyrrole, pyridone & 0.9 & 42 \\
\hline & $399.0 \pm 0.2$ & Pyridine, Imine & 1.0 & 41 \\
\hline & $402.7 \pm 0.2$ & Oxidized N & 0.3 & 14 \\
\hline \multirow[t]{3}{*}{ KUA-N_800 } & $400.8 \pm 0.2$ & Pyrrole, Pyridone & 1.2 & 51 \\
\hline & $398.7 \pm 0.2$ & Pyridine & 0.8 & 35 \\
\hline & $400.7 \pm 0.2$ & Pyrrole, pyridone & 0.7 & 19 \\
\hline \multirow[t]{3}{*}{$\mathrm{KUA}-\mathrm{CONH}_{2}$} & $399.8 \pm 0.2$ & Amide, lactam, amine, imide & 1.9 & 50 \\
\hline & $398.8 \pm 0.2$ & Pyridine, imine & 1.2 & 31 \\
\hline & $400.9 \pm 0.2$ & Pyrrole, pyridone & 1.7 & 34 \\
\hline \multirow{3}{*}{ KUA-CONH $2 \_500$} & $399.6 \pm 0.2$ & Amide, lactam, amine, imide & 1.3 & 38 \\
\hline & $398.5 \pm 0.2$ & Pyridine, imine & 1.0 & 28 \\
\hline & $402.5 \pm 0.2$ & Oxidized N & 0.2 & 11 \\
\hline \multirow{2}{*}{$\mathrm{KUA}-\mathrm{CONH}_{2} \_800$} & $400.8 \pm 0.2$ & Pyrrole, pyridone & 0.9 & 52 \\
\hline & $398.7 \pm 0.2$ & Pyridine, imine & 0.6 & 37 \\
\hline
\end{tabular}

The heat treatments at $800{ }^{\circ} \mathrm{C}$ strongly decrease the nitrogen groups of the $\mathrm{N}$-doped samples (Table 2, Figure 4). The samples KUA-N_800 and $\mathrm{KUA}-\mathrm{CONH}_{2} 800$ show similar nitrogen content (1.7 at. \% and 2.1 at. \%, respectively, Table 2$)$ and distribution of functionalities, with a main contribution of pyrroles/pyridones and a lower presence of pyridines and quaternary nitrogen (Table 3 ). These modifications are undoubtedly related to the removal of nitrogen groups of lower thermal stability as well as their conversion into more stable groups, such as nitrogen heterocycles [35].

Thus, the combination of nitrogen doping at mild conditions with post-thermal treatments allow the production of activated carbon with similar microporosity and different surface functionalities. Hence, their electrochemical characterization in organic electrolyte can be useful to get information about the role of the different $\mathrm{N}$ functional groups in the electrochemical performance of the materials as electrodes for supercapacitors.

\subsection{Electrochemical Characterization}

The electrochemical performance of the samples was evaluated as electrodes in the EDLC (activated carbon-based symmetric electrochemical capacitors) with organic electrolyte (1M TEMABF $4 / \mathrm{PC})$ by using a two-electrode cell configuration. The cells were tested by GCD cycles at different current densities. Table 4 collects the capacitance and energy obtained from the galvanostatic test and Figure 5 shows, as an example, some of the charge-discharge curves obtained for the capacitors at $40 \mathrm{~mA} / \mathrm{g}$. The curves evidence an ideal capacitive behaviour, characterized by the triangular shape, for all the activated carbon-based capacitors. All of them provide large capacitance (36-41 F/g) and gravimetric energy density $(32-37 \mathrm{Wh} / \mathrm{kg}$ ) as consequence of their well-developed microporosity. The small differences found between the samples are related to their slightly different apparent surface area, as confirmed by the similar surface capacitance values (specific capacitance per surface area) obtained for these materials $\left(13-15 \mu \mathrm{F} / \mathrm{cm}^{2}\right)$. The nitrogen doping does not produce an increase of capacitance as observed in other $\mathrm{N}$-doped carbons $[7,18]$ since the large microporosity development of these materials might mitigate this effect. Interestingly, the lowest values were obtained for the non-doped samples with a higher oxygen content (KUA and KUA-COOH), evidencing a detrimental effect derived from these functional groups [21]. 
Table 4. Gravimetric capacitance, surface capacitance, energy density, retention of capacitance at $1000 \mathrm{~mA} / \mathrm{g}\left(C_{1} / C_{0}\right)$, retention of capacitance after floating test $\left(C_{\mathrm{f}} / C_{0}\right)$, increase of resistance and integrated leakage current obtained for all EDLCs. $\mathrm{V}=2.5 \mathrm{~V} . \mathrm{j}=40 \mathrm{~mA} / \mathrm{g}$.

\begin{tabular}{|c|c|c|c|c|c|c|c|}
\hline Capacitor & $C_{0}(\mathrm{~F} / \mathrm{g})$ & $C_{0} / S_{\text {BET }}\left(\mu \mathrm{F} / \mathrm{cm}^{2}\right)$ & $E(\mathrm{Wh} / \mathrm{kg})$ & $C_{1} / C_{0}(\%)$ & $C_{\mathrm{f}} / C_{0}(\%)$ & $\Delta R(\Omega)$ & $I_{L}(\mathrm{mAh})$ \\
\hline KUA & 41 & 13 & 37 & 45 & 29 & 33 & 37 \\
\hline KUA_800 & 38 & 14 & 33 & 48 & 43 & 30 & 29 \\
\hline KUA-N & 41 & 14 & 36 & 42 & 39 & 20 & 32 \\
\hline KUA-N_500 & 41 & 15 & 35 & 45 & 39 & 32 & 36 \\
\hline KUA-N_800 & 40 & 14 & 35 & 49 & 44 & 28 & 31 \\
\hline KUA-COOH & 36 & 13 & 31 & 30 & 20 & 50 & 26 \\
\hline $\mathrm{KUA}-\mathrm{CONH}_{2}$ & 37 & 15 & 32 & 49 & 55 & 13 & 22 \\
\hline KUA-CONH ${ }_{2} \_500$ & 39 & 15 & 33 & 37 & 22 & 86 & 33 \\
\hline KUA-CONH ${ }_{2} \_800$ & 38 & 15 & 32 & 42 & 33 & 34 & 41 \\
\hline
\end{tabular}
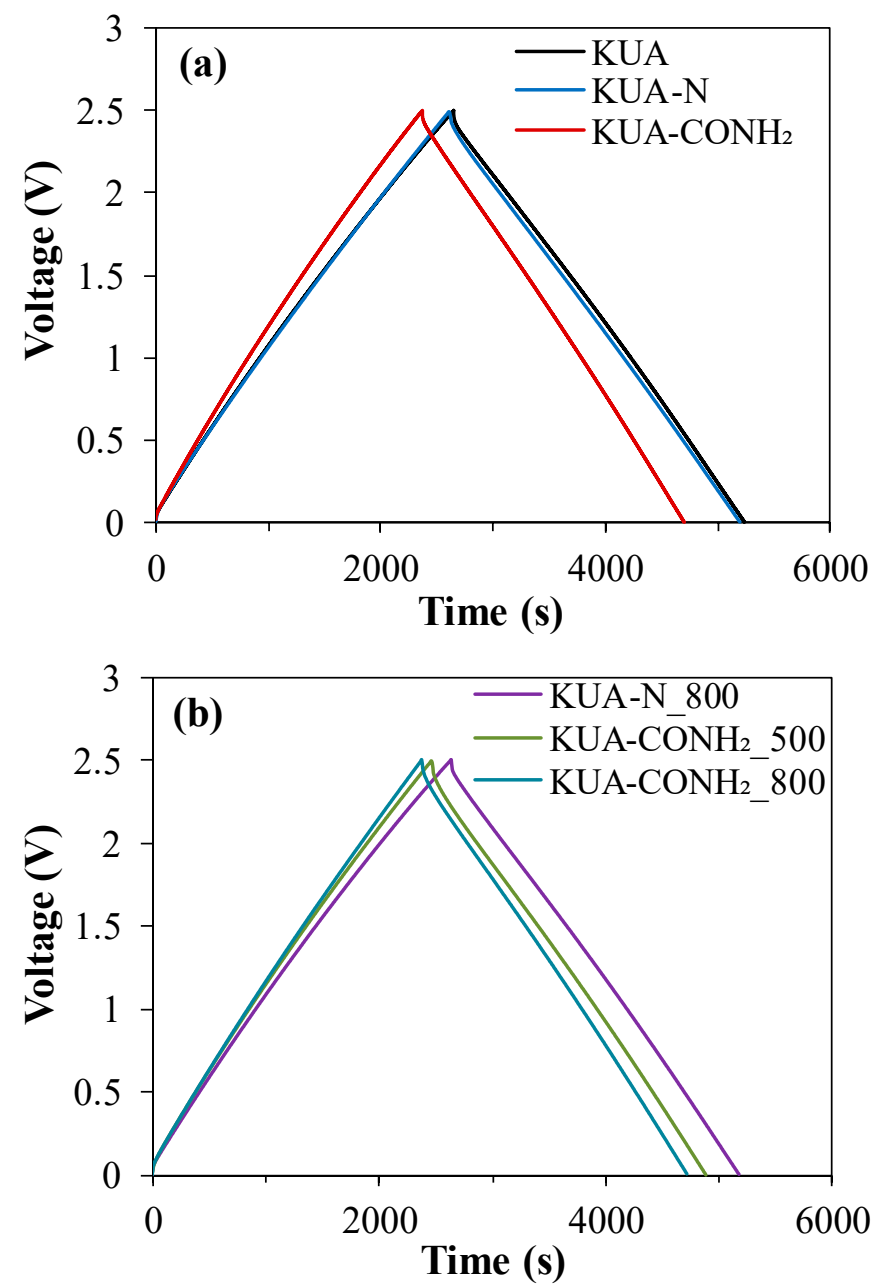

Figure 5. GCD curves obtained for selected EDLCs (activated carbons-based symmetric capacitors): (a) KUA, KUA-N and KUA-CONH 2 based capacitors; (b) KUA-N_800, KUA-CONH 2 500 and KUA-CONH 2 _800. $1 \mathrm{M} \mathrm{TEMABF} 4$ /PC. j $=40 \mathrm{~mA} / \mathrm{g}$. V $=2.5 \mathrm{~V}$.

Figure 6 shows the evolution of the capacitance when increasing the current density during the galvanostatic cycling test. The GCD cycles recorded at high current density are shown in Figure S2 in the Supplementary Data. The oxidation process produces a detrimental effect on the rate performance of KUA-COOH when used as electrode for supercapacitors. Moreover, when the amidation treatment is carried out, the replacement of oxygen groups by nitrogen functionalities with a higher conductivity (cyclic amides, pyrroles, etc.) $[18,39]$ improves the behaviour, and consequently, a higher capacitance is retained when the current density is increased (Figure 6a, Table 4 , column $C_{1} / C_{0}$ ). The same trend 
was observed in aqueous electrolyte [28]. The heat treatments of the activated carbons, which remove oxygen functionalities, produce an improvement of the rate performance, but the benefits by the heat-treatment is not significant for the $\mathrm{N}$-doped samples (Figure $6 \mathrm{~b}$, Table 4 , column $C_{1} / C_{0}$ ). Hence, the increase of the charge-discharge rate is mainly a consequence of an increase of conductivity due to the removal of electron-withdrawing oxygen functionalities.
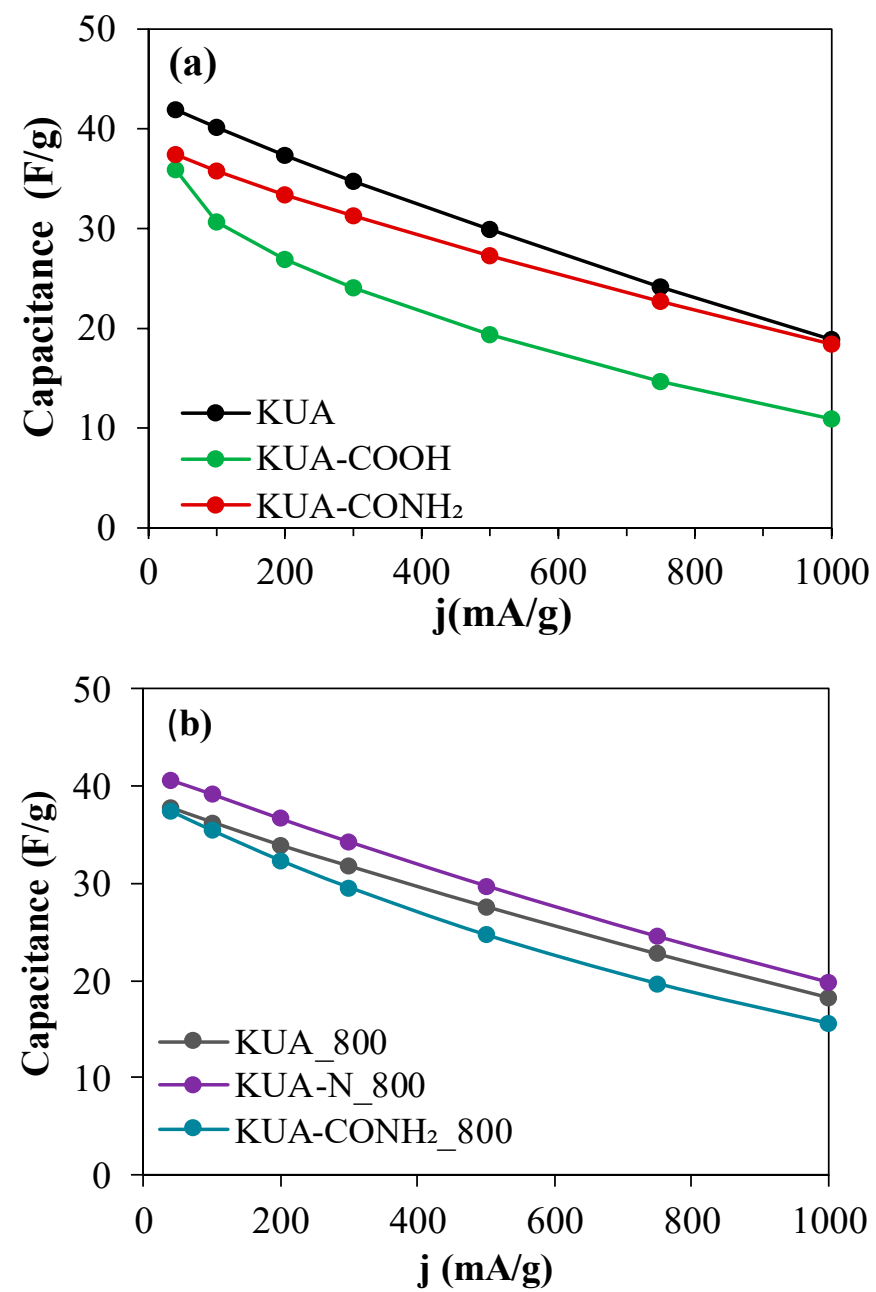

Figure 6. Rate performance (dependence of gravimetric capacitance on current densities) for selected EDLCs: (a) KUA, KUA-COOH and KUA-CONH ${ }_{2}$; (b) KUA_800, KUA-N_800 and KUA-CONH 2800 . $1 \mathrm{M} \mathrm{TEMABF}_{4} / \mathrm{PC} . \mathrm{j}=40,100,200,500,750$ and $1000 \mathrm{~mA} / \mathrm{g} . \mathrm{V}=2.5 \mathrm{~V}$.

The EDLCs were submitted to a durability test to assess the effect of surface chemistry in the electrochemical stability of the carbon materials. The most common method for the assessment of the durability of energy storage devices consists in applying thousands of GCD cycles at the operative voltage of the devices [10]. Since capacitors are based in electrostatic processes and consequently provide a much larger cycle life than batteries, this methodology is considerably more time demanding for supercapacitors [1]. An alternative to this procedure is the use of a floating test, consisting in keeping the cell charged during long time in order to accelerate the degradation of the device [40-44]. Moreover, it is well-known that electrochemical capacitors experience degradation at high temperature $[6,21,45,46]$. Hence, the combination of high voltage holding with the use of high temperature constitutes an adequate procedure to accelerate the degradation of electrochemical capacitors.

Figure 7 shows, as an example, the evolution of capacitance and coulombic efficiency during the steps of the durability test (described in Section 2.3.) for some of the capacitors. Table 4 compiles the parameters (retention of capacitance $\left(C_{\mathrm{f}} / C_{0}\right)$, increase of resistance $(\Delta R)$ and integrated leakage current 
$\left.\left(I_{L}\right)\right)$ related to this test determined for all capacitors. The analysis of these data allows for a thorough discussion of the effect of surface chemistry modification on the performance of carbon materials as electrodes for supercapacitors in organic electrolyte.
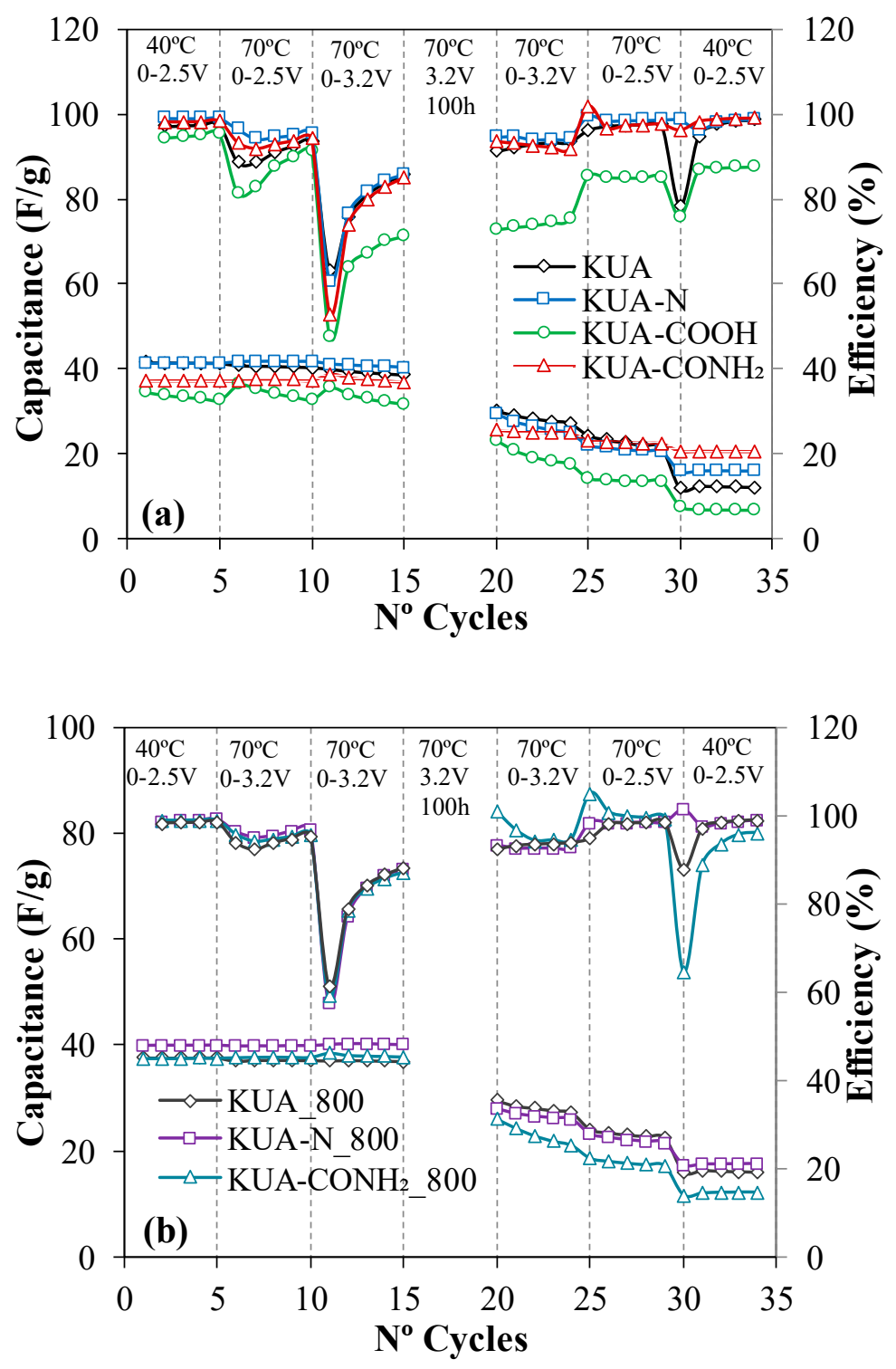

Figure 7. Evolution of capacitance and coulombic efficiency during the durability test for selected EDLCs: (a) KUA, KUA-N, KUA-COOH and $\mathrm{KUA}-\mathrm{CONH}_{2}$; (b) KUA_800, KUA-N_800 and KUA-CONH 28800 . $1 \mathrm{M} \mathrm{TEMABF}_{4} / \mathrm{PC}$. j $=40 \mathrm{~mA} / \mathrm{g}$.

\subsubsection{Effect of Surface Chemistry Modification at Mild Conditions}

Figure 7a displays the performance of the pristine carbon material during the durability test. The test starts with a conventional galvanostatic cycling step at $40{ }^{\circ} \mathrm{C}$ and $2.5 \mathrm{~V}$, followed by two steps at increased temperature $\left(70{ }^{\circ} \mathrm{C}\right)$ and loading voltage $\left(3.2 \mathrm{~V}\right.$ and $\left.70^{\circ} \mathrm{C}\right)$ conditions. Such increases do not affect the gravimetric capacitance, but they have a negative impact on the coulombic efficiency evidencing the occurrence of faradaic processes under these conditions. After these steps, a floating test of $100 \mathrm{~h}$ takes part at rather severe conditions $\left(3.2 \mathrm{~V}\right.$ and $\left.70{ }^{\circ} \mathrm{C}\right)$. The harmful effect of the floating conditions is clearly observed in the capacitance values determined after the durability test. For the pristine sample, only a $29 \%$ of capacitance is retained after the ageing test. 
In general, the $\mathrm{N}$-doped samples show a similar trend for the durability to the pristine samples. Thus, a remarkable loss of capacitance (50-70\%) is detected after the floating test for all supercapacitors (Table 4). The differences in the performance are a consequence of their different surface chemistry. First, it is confirmed that the oxidation process strongly affects the behavior of the capacitor, since a retention of capacitance of $20 \%$ and an increase of resistance of $50 \Omega$ is detected for KUA-COOH based capacitor. Thus, the ageing protocol produces an enormous degradation of the electrodes due to reaction between the electrolyte and the oxygen groups present on the surface of the electrodes [21]. Otherwise, the $\mathrm{N}$-doping treatments at mild conditions improve the performance of the carbon materials. Especially, $\mathrm{KUA}-\mathrm{CONH}_{2}$ based capacitor shows the best performance of all tested cells (Table 4). The retention of capacitance obtained is $55 \%$, which means an increase of $26 \%$ in comparison with the pristine carbon-based capacitor (KUA). Moreover, the $\mathrm{KUA}-\mathrm{CONH}_{2}$ based capacitor shows the lowest integrated leakage current, which is associated to the occurrence of undesired faradaic reactions during the charging of the device (oxidation, gasification, etc.) [7,44]. As discussed in Section 3.1.2., KUA-CONH${ }_{2}$ shows predominance of amide-like functional groups as well as a lower amount of nitrogen heterocycles (pyridines and pyrroles/pyridones). Also, the sample has a larger content of oxygen functional groups than the pristine sample as consequence of the oxidation process carried out prior to the amidation. However, the increase in stability cannot be related to the oxygen functionalities since they damage the electrochemical stability, as evidenced by KUA-COOH based capacitor. Actually, the capacitance retention detected for $\mathrm{KUA}-\mathrm{CONH}_{2}$ is even higher (36\%) when compared to the former oxidized sample KUA-COOH. Thus, the improvement of the performance is undoubtedly related to the generation of stable nitrogen surface functional groups.

Furthermore, KUA-N based capacitor also has better performance than the pristine carbon-based capacitor (Figure 7a, Table 4), evidencing an increase of capacitance retention of $11 \%$. Since this sample is synthesized by a direct replacement of oxygen groups by nitrogen functionalities of KUA, the improvement might be a result of the combined effect caused by the removal of detrimental oxygen groups and generation of nitrogen moieties with higher electrochemical stability (pyrroles, pyridines, etc.). Moreover, the comparison of the N-doped samples (KUA-N and KUA-CONH${ }_{2}$ ) allows to distinguish the effect of the different nitrogen functional groups and evidence a remarkable stabilizing effect related to amides and cycles amides, since these functional groups exist with the highest amount on the surface of $\mathrm{KUA}-\mathrm{CONH}_{2}$ and the corresponding capacitor shows a higher retention of capacitance and a lower increase of resistance than KUA-N based capacitor. This result can be considered as unusual since amide functional groups shows lower thermal stability than other nitrogen functionalities [35]. However, their cyclic forms (such as lactams) show larger thermal stability due to the incorporation of $\mathrm{N}$ heterocycles at the edge of the carbon layer. Moreover, they are tautomeric forms of pyridones, which provide larger thermal stability [28]. Although thermal and electrochemical stability might not be intrinsically related, these facts can help to clarify the improved performance showed by amide-functionalized activated carbon electrodes.

In order to deepen into the role of the different functionalities, the effect of heat treatments on the performance of activated carbons as electrodes for supercapacitors is thoroughly discussed.

\subsubsection{Effect of Surface Chemistry Modification by Heat Treatments}

The durability of the capacitors built with the heat-treated samples was also analyzed (Figure $7 \mathrm{~b}$ ) and the related parameters are collected in Table 4. Some meaningful differences are found when comparing the capacitor performance of the samples heat treated at $500{ }^{\circ} \mathrm{C}$. KUA-N_500 based capacitor has better performance than the pristine carbon material KUA, as denoted by an increase of retention of capacitance of $10 \%$. This sample has a similar surface chemistry to the parent KUA-N, with slightly lower content of oxygen and nitrogen groups (Section 3.1.2.). Thus, the improvement is related, again, to the removal of detrimental oxygen functional groups as well as the generation of more stable nitrogen groups. Nevertheless, the analogous $\mathrm{KUA}-\mathrm{CONH}_{2} 500$ based capacitor shows lower stability through the durability test $(22 \%$ of capacitance retention, Table 4$)$ than the 
related carbon-based capacitors. Interestingly, the heat-treated N-doped carbons (KUA-CONH $2 \_500$ and KUA-N_500) show different behavior upon durability even though their surface chemistry is almost identical in terms of amount of oxygen and nitrogen heteroatoms (Section 3.1.2). The main difference arises from their parent carbons (KUA-CONH${ }_{2}$ and $\mathrm{KUA}-\mathrm{N}$ ). $\mathrm{KUA}-\mathrm{CONH}_{2}$ has a larger amount of surface functionalities, that upon heating may decompose and generate a larger number of reactive sites. Consequently, the capacitor based on the activated carbon prepared by the heat treatment of $\mathrm{KUA}-\mathrm{CONH}_{2}$ might experience more interactions with the electrolyte, leading to a higher degradation process.

The heat treatment of the samples at $800^{\circ} \mathrm{C}$ also affect the durability of the devices. It is clearly observed that the treatment under these conditions improve the performance as consequence of the high decrease of oxygen functionalities. Thus, KUA_800 and KUA-N_800 have a similar behavior upon the floating test, with an increase of retention of capacitance of $\sim 14 \%$ for both capacitors (in comparison with KUA-based capacitor). Hence, no further improvement results from the nitrogen groups present on KUA-N_800. In case of KUA-CONH $2 \_800$ based capacitor, the values of retention of capacitance are higher than the heat treated at $500{ }^{\circ} \mathrm{C}$ due to the generation of surface functionalities with higher electrochemical stability at this temperature (pyrroles/pyridones). However, the performance is still poorer than that found for the capacitors based on heat treated carbons at $800{ }^{\circ} \mathrm{C}$ (KUA_800 and KUA-N_800), since the surface reactivity of this heat treated carbon material is higher than the found in the related materials.

These results point out that heat treatments improve the performance of carbon electrodes upon durability mostly due to the removal of detrimental oxygen functionalities. However, the performance is further improved when the doping strategies are carried out by wet methods at low temperature. KUA-N and $\mathrm{KUA}-\mathrm{CONH}_{2}$ show better performance than the related heat-treated samples not only in terms of retention of capacitance but also in the increase of resistance. Indeed, the supercapacitors constructed from both N-doped carbons show the lowest increase of resistance of the whole series. This is a consequence of combining the beneficial effect of the decrease in the most reactive oxygen groups with the production of nitrogen functional groups with remarkable stabilizing effect, especially in the case of amide-like functionalities. Also, the generation of reactive sites during the thermal treatment is avoided under these mild conditions. Thus, the nitrogen doping method at mild conditions is a promising strategy to improve the performance of any carbon material as electrode for supercapacitors.

As a proof of concept, a commercial activated carbon used for supercapacitor application was successfully functionalized with nitrogen and tested for durability in organic electrolyte (see Supplementary Data II, Figures S4-S6, Table S1). After the durability test, an increase of retention of capacitance of $7 \%$ was determined, confirming the viability of this methodology to improve the electrochemical stability of carbon materials.

\section{Conclusions}

Activated carbons with a similar porosity but different surface chemistry have been prepared by combining chemical functionalization methods at mild conditions and post-thermal treatments. The doping methods at low temperature provide the incorporation of $\sim 4 \%$ at. of $\mathrm{N}$ in form of different functionalities by consumption of oxygen moieties. The heat treatments diminish the content of heteroatom-containing surface functionalities and produce rearrangements of the nitrogen groups. The surface composition and porosity of the heat-treated samples is almost identical for the whole series of carbons.

The surface chemistry of these carbon materials clearly influences the electrochemical performance when tested as electrodes for the EDLC in organic electrolyte. They show large capacitance values with no significant differences as a consequence of their similar porous texture. The presence of oxygen functional groups affects the rate performance of the capacitor due to the decrease of 
conductivity, while nitrogen functional groups (cyclic amides, pyridines, and pyrroles) slightly increase the conductivity of the carbon material.

The effect of surface functionalities upon durability was thoroughly studied. The oxygen functionalities strongly damage the performance of the activated carbons. Thus, the heat treatments of the samples produce an improvement of the electrochemical stability due to the decrease of detrimental oxygen groups. However, the performance is further increased by nitrogen doping at mild conditions, since the treatment combines the positive effect of removing the most reactive oxygen groups with their replacement by nitrogen groups with high electrochemical stability, which is especially beneficial in case of the generation of amide-like functional groups.

Supplementary Materials: The following are available online at http://www.mdpi.com/2311-5629/6/3/56/s1, Figure S1. Differential pore size distributions obtained by NL-DFT calculations for all activated carbons; Figure S2. GCD curves obtained for EDLCs (activated carbons-based symmetric capacitors). 1M TEMABF4/PC. $\mathrm{j}=1000 \mathrm{~mA} / \mathrm{g}$. $\mathrm{V}=2.5 \mathrm{~V}$; Figure S3. N1s XPS spectrum obtained for YP50F-N activated carbon; Figure S4. N2 adsorption-desorption isotherms of the activated carbons YP50F and YP50F-N; Figure S5. Cyclic voltammograms in the potential range between $0 \mathrm{~V}$ and $0.6 \mathrm{~V}$ for YP50F and YP50F-N electrodes. $1 \mathrm{M} \mathrm{H} 2 \mathrm{SO}$. V=1 mV/s; Figure S6. Evolution of capacitance and coulombic efficiency during the durability test for YP50F and YP50F-N based capacitors. $1 \mathrm{M}$ TEMABF4. $\mathrm{j}=40 \mathrm{~mA} / \mathrm{g}$; Table S1. Textural properties and elemental surface composition (XPS and TPD) for YP50F and YP50F-N.

Author Contributions: Conceptualization, D.C.-A., E.M., and S.S.; Formal analysis, M.J.M.-L., R.R.-R., and T.T.; Funding acquisition, D.C.-A., E.M., and S.S.; Investigation, M.J.M.-L., R.R.-R., T.T., Y.H., S.S., E.M., and D.C.-A.; Methodology, M.J.M.-L., R.R.-R., T.T., Y.H., and D.C.-A.; Resources, D.C.-A., E.M., and S.S.; Writing-original draft, M.J.M.-L., R.R.-R., T.T., and Y.H.; Writing-review \& editing, D.C.-A., E.M., and S.S. All authors have read and agreed to the published version of the manuscript.

Funding: This research was funded by MINECO, FEDER (CTQ2015-66080-R (MINECO/FEDER), RTI2018-095291-B-I00, ENE2017-90932-REDT, PID2019-105923RB-I00), JSPS KAKENHI (17H03123), and Gunma University Element Functional Science Project. MJML was funded by VALi+d grant (ACIF/2015/374) and mobility grant (BEFPI/2016/006).

Acknowledgments: The authors thank MINECO, FEDER (CTQ2015-66080-R (MINECO/FEDER), RTI2018-095291-B-I00, ENE2017-90932-REDT, PID2019-105923RB-I00), JSPS KAKENHI (17H03123), and Gunma University Element Functional Science Project. MJML acknowledges financial support throught VALi+d grant (ACIF/2015/374) and mobility grant (BEFPI/2016/006).

Conflicts of Interest: The authors declare no conflict of interest.

\section{References}

1. Conway, B.E. Electrochemical Supercapacitors: Scientific Fundamentals and Technological Applications; Springer: New York, NY, USA, 1999.

2. Raza, W.; Ali, F.; Raza, N.; Luo, Y.; Kim, K.-H.; Yang, J.; Kumara, S.; Mehmood, A.; Kwon, E.E. Recent advancements in supercapacitor technology. Nano Energy 2018, 52, 441-473. [CrossRef]

3. Béguin, F.; Frackowiak, E. (Eds.) Carbons for Electrochemical Energy Storage and Conversion Systems, 1st ed.; CRC Press: Boca Raton, FL, USA, 2009.

4. Le, T.X.H.; Bechelany, M.; Cretin, M. Carbon felt based-electrodes for energy and environmental applications: A review. Carbon 2017, 122, 564-591. [CrossRef]

5. Balducci, A. Electrolytes for high voltage electrochemical double layer capacitors: A perspective article. J. Power Sources 2016, 326, 534-540. [CrossRef]

6. Béguin, F.; Presser, V.; Balducci, A.; Frackowiak, E. Carbons and Electrolytes for Advanced Supercapacitors. Adv. Mater. 2014, 26, 2219-2251. [CrossRef] [PubMed]

7. Salinas-Torres, D.; Shiraishi, S.; Morallón, E.; Cazorla-Amoros, D. Improvement of carbon materials performance by nitrogen functional groups in electrochemical capacitors in organic electrolyte at severe conditions. Carbon 2015, 82, 205-213. [CrossRef]

8. Shiraishi, S. Heat-Treatment and Nitrogen-Doping of Activated Carbons for High Voltage Operation of Electric Double Layer Capacitor. Key Eng. Mater. 2011, 497, 80-86. [CrossRef]

9. Mostazo-López, M.J.; Ruiz-Rosas, R.; Morallón, E.; Cazorla-Amoros, D. Nitrogen doped superporous carbon prepared by a mild method. Enhancement of supercapacitor performance. Int. J. Hydrogen Energy 2016, 41, 19691-19701. [CrossRef] 
10. Frackowiak, E.; Béguin, F. Carbon materials for the electrochemical storage of energy in capacitors. Carbon 2001, 39, 937-950. [CrossRef]

11. Paraknowitsch, J.P.; Thomas, A. Doping carbons beyond nitrogen: An overview of advanced heteroatom doped carbons with boron, sulphur and phosphorus for energy applications. Energy Environ. Sci. 2013, 6, 2839. [CrossRef]

12. Yang, Z.; Nie, H.; Chen, X.; Chen, X.; Huang, S. Recent progress in doped carbon nanomaterials as effective cathode catalysts for fuel cell oxygen reduction reaction. J. Power Sources 2013, 236, 238-249. [CrossRef]

13. Berenguer, R.; Ruiz-Rosas, R.; Gallardo, A.; Cazorla-Amoros, D.; Morallón, E.; Nishihara, H.; Kyotani, T.; Rodríguez-Mirasol, J.; Cordero, T. Enhanced electro-oxidation resistance of carbon electrodes induced by phosphorus surface groups. Carbon 2015, 95, 681-689. [CrossRef]

14. González-Gaitán, C.; Ruiz-Rosas, R.; Nishihara, H.; Kyotani, T.; Morallón, E.; Cazorla-Amoros, D. Successful functionalization of superporous zeolite templated carbon using aminobenzene acids and electrochemical methods. Carbon 2016, 99, 157-166. [CrossRef]

15. Ornelas, O.; Sieben, J.M.; Ruiz-Rosas, R.; Morallón, E.; Cazorla-Amoros, D.; Geng, J.; Soin, N.; Siores, E.; Johnson, B.F.G. On the origin of the high capacitance of nitrogen-containing carbon nanotubes in acidic and alkaline electrolytes. Chem. Commun. 2014, 50, 11343-11346. [CrossRef] [PubMed]

16. Le, T.-X.-H.; Esmilaire, R.; Drobek, M.; Bechelany, M.; Vallicari, C.; Cerneaux, S.; Julbe, A.; Cretin, M. Nitrogen-Doped Graphitized Carbon Electrodes for Biorefractory Pollutant Removal. J. Phys. Chem. C 2017, 121, 15188-15197. [CrossRef]

17. Mostazo-López, M.J.; Ruiz-Rosas, R.; Castro-Muñiz, A.; Nishihara, H.; Kyotani, T.; Morallón, E.; Cazorla-Amoros, D. Ultraporous nitrogen-doped zeolite-templated carbon for high power density aqueous-based supercapacitors. Carbon 2018, 129, 510-519. [CrossRef]

18. Hulicova-Jurcakova, D.; Kodama, M.; Shiraishi, S.; Hatori, H.; Zhu, Z.; Lu, G. Nitrogen-Enriched Nonporous Carbon Electrodes with Extraordinary Supercapacitance. Adv. Funct. Mater. 2009, 19, 1800-1809. [CrossRef]

19. Candelaria, S.L.; Garcia, B.B.; Liu, D.; Cao, G. Nitrogen modification of highly porous carbon for improved supercapacitor performance. J. Mater. Chem. 2012, 22, 9884. [CrossRef]

20. Kawaguchi, M.; Yamanaka, T.; Hayashi, Y.; Oda, H. Preparation and Capacitive Properties of a Carbonaceous Material Containing Nitrogen. J. Electrochem. Soc. 2010, 157, A35. [CrossRef]

21. Cazorla-Amoros, D.; Lozano-Castelló, D.; Morallón, E.; Bleda-Martínez, M.J.; Linares-Solano, A.; Shiraishi, S. Measuring cycle efficiency and capacitance of chemically activated carbons in propylene carbonate. Carbon 2010, 48, 1451-1456. [CrossRef]

22. Raymundo-Piñero, E.; Kierzek, K.; Machnikowski, J.; Béguin, F. Relationship between the nanoporous texture of activated carbons and their capacitance properties in different electrolytes. Carbon 2006, 44, 2498-2507. [CrossRef]

23. Shen, W.; Fan, W. Nitrogen-containing porous carbons: Synthesis and application. J. Mater. Chem. A 2013, 1, 999-1013. [CrossRef]

24. Deng, Y.; Zou, K.; Xie, Y.; Ji, X. Review on recent advances in nitrogen-doped carbons: Preparations and applications in supercapacitors. J. Mater. Chem. A 2016, 4, 1144-1173. [CrossRef]

25. Raymundo-Piñero, E.; Cazorla-Amoros, D.; Linares-Solano, A. The role of different nitrogen functional groups on the removal of $\mathrm{SO} 2$ from flue gases by $\mathrm{N}$-doped activated carbon powders and fibres. Carbon 2003, 41, 1925-1932. [CrossRef]

26. Itoi, H.; Nishihara, H.; Kyotani, T. Effect of Heteroatoms in Ordered Microporous Carbons on Their Electrochemical Capacitance. Langmuir 2016, 32, 11997-12004. [CrossRef]

27. Nishihara, H.; Hou, P.-X.; Li, L.-X.; Ito, M.; Uchiyama, M.; Kaburagi, T.; Ikura, A.; Katamura, J.; Kawarada, T.; Mizuuchi, K.; et al. High-Pressure Hydrogen Storage in Zeolite-Templated Carbon. J. Phys. Chem. C 2009, 113, 3189-3196. [CrossRef]

28. Mostazo-López, M.J.; Ruiz-Rosas, R.; Morallón, E.; Cazorla-Amoros, D. Generation of nitrogen functionalities on activated carbons by amidation reactions and Hofmann rearrangement: Chemical and electrochemical characterization. Carbon 2015, 91, 252-265. [CrossRef]

29. Tagaya, T.; Hatakeyama, Y.; Shiraishi, S.; Tsukada, H.; Mostazo-López, M.J.; Morallón, E.; Cazorla-Amorós, D. Nitrogen-Doped Seamless Activated Carbon Electrode with Excellent Durability for Electric Double Layer Capacitor. J. Electrochem. Soc. 2020, 167, 060523. [CrossRef] 
30. Lozano-Castelló, D.; Lillo-Ródenas, M.A.; Cazorla-Amoros, D.; Linares-Solano, A. Preparation of activated carbons from Spanish anthracite. Carbon 2001, 39, 741-749. [CrossRef]

31. Cazorla-Amoros, D.; Alcañiz-Monge, J.; de La de La Casa-Lillo, M.A.; Linares-Solano, A. CO2As an Adsorptive to Characterize Carbon Molecular Sieves and Activated Carbons. Langmuir 1998, 14, 4589-4596. [CrossRef]

32. Lozano-Castelló, D.; Cazorla-Amoros, D.; Linares-Solano, A.; Shiraishi, S.; Kurihara, H.; Oya, A. Influence of pore structure and surface chemistry on electric double layer capacitance in non-aqueous electrolyte. Carbon 2003, 41, 1765-1775. [CrossRef]

33. Bleda-Martínez, M.; Lozano-Castelló, D.; Morallón, E.; Cazorla-Amoros, D.; Linares-Solano, A. Chemical and electrochemical characterization of porous carbon materials. Carbon 2006, 44, 2642-2651. [CrossRef]

34. Raymundo-Piñero, E.; Cazorla-Amoros, D.; Linares-Solano, A.; Find, J.; Wild, U.; Schlögl, R. Structural characterization of $\mathrm{N}$-containing activated carbon fibers prepared from a low softening point petroleum pitch and a melamine resin. Carbon 2002, 40, 597-608. [CrossRef]

35. Jansen, R.; van Bekkum, H. XPS of nitrogen-containing functional groups on activated carbon. Carbon 1995, 33, 1021-1027. [CrossRef]

36. Yamada, Y.; Kim, J.; Matsuo, S.; Sato, S. Nitrogen-containing graphene analyzed by X-ray photoelectron spectroscopy. Carbon 2014, 70, 59-74. [CrossRef]

37. Figueiredo, J.; Pereira, M.F.R.; Freitas, M.M.; Órfão, J.J.D.M. Modification of the surface chemistry of activated carbons. Carbon 1999, 37, 1379-1389. [CrossRef]

38. Arrigo, R.; Hävecker, M.; Wrabetz, S.; Blume, R.; Lerch, M.; McGregor, J.; Parrott, E.P.J.; Zeitler, J.A.; Gladden, L.; Knop-Gericke, A.; et al. Tuning the Acid/Base Properties of Nanocarbons by Functionalization via Amination. J. Am. Chem. Soc. 2010, 132, 9616-9630. [CrossRef]

39. Strelko, V.V.; Kuts, V.S.; Thrower, P.A. On the mechanism of possible influence of heteroatoms of nitrogen, boron and phosphorus in a carbon matrix on the catalytic activity of carbons in electron transfer reactions. Carbon 2000, 38, 1499-1503. [CrossRef]

40. Shiraishi, S. Electrochemical Performance. In Materials Science and Engineering of Carbon; Inagaki, M., Ed.; Tsinghua University Press Limited: Beijing, China; Elsevier Inc.: Amsterdam, The Netherlands, 2016; pp. 205-226.

41. Weingarth, D.; Noh, H.; Foelske, A.; Wokaun, A.; Kötz, R. A reliable determination method of stability limits for electrochemical double layer capacitors. Electrochim. Acta 2013, 103, 119-124. [CrossRef]

42. Weingarth, D.; Foelske, A.; Kötz, R. Cycle versus voltage hold-Which is the better stability test for electrochemical double layer capacitors? J. Power Sources 2013, 225, 84-88. [CrossRef]

43. Ruch, P.W.; Cericola, D.; Foelske-Schmitz, A.; Kotz, R.; Wokaun, A. Aging of electrochemical double layer capacitors with acetonitrile-based electrolyte at elevated voltages. Electrochim. Acta 2010, 55, 4412-4420. [CrossRef]

44. Ratajczak, P.; Jurewicz, K.; Béguin, F. Factors contributing to ageing of high voltage carbon/carbon supercapacitors in salt aqueous electrolyte. J. Appl. Electrochem. 2013, 44, 475-480. [CrossRef]

45. Kotz, R.; Hahn, M.; Gallay, R. Temperature behavior and impedance fundamentals of supercapacitors. J. Power Sources 2006, 154, 550-555. [CrossRef]

46. Bohlen, O.; Kowal, J.; Sauer, D.U. Ageing behaviour of electrochemical double layer capacitors. J. Power Sources 2007, 172, 468-475. [CrossRef]

(C) 2020 by the authors. Licensee MDPI, Basel, Switzerland. This article is an open access article distributed under the terms and conditions of the Creative Commons Attribution (CC BY) license (http://creativecommons.org/licenses/by/4.0/). 